\title{
A Brief Analysis of the Cultural Connotation and Characteristics of the Urban Sculpture Culture of Mengzi City
}

Zong.Yan

\section{Honghe.University.Yunnan.China \\ Email: 22869555@qq.com}

\begin{abstract}
Mengzi is a developing medium-sized city with long history and massive culture. Along with the development, the image of the city has got ascended rapidly. The city's sculpture has got certain development. Mengzi is a culture famous city in southwest China with many the firsts of Yunnan Province. The outstanding characteristic cultures are: the French concession culture, the Southwest Associated University culture, the Yunnan Rice Noodles culture and the pomegranate culture. Most urban sculptures are around those important cultures. By looking up to the documents, and making fact-finding survey, the state-of-the-art, the distribution and the variety of the sculptures in Mengzi are analyzed. Some typical cases are analyzed and compared. The cultural features are considered to analyze the art characteristic and cultural connotation of the sculptures in Mengzi.
\end{abstract}

Key words: Mengzi City; urban sculpture; cultural connotation; art feature

\section{A Survey of the Urban Sculpture in Mengzi}

\subsection{The Culture Background of Mengzi}

Mengzi is an important town in southern Yunnan, which has a long history. It has abundant resources and prosperous culture. In the history of more than 2000 years, it sets multiculture, such as the borderland culture, the central plain culture, the Party's history culture, the brigade culture, and the western culture as a rich ore with thick historical accumulation and various cultural resources. The culture of Mengzi is approximately divided into the French concession culture, the Southwest Associated University culture, the Yunnan Rice Noodles culture and the pomegranate culture.

\subsection{The variety of the urban sculpture of Mengzi.}

The good and bad of a city's urban sculpture shows not only on the clear-cut theme, new and interesting approach, but also the embodiment of the region and the expression of the culture. It's the soul of the city, the cultural of the urban sculpture. The urban sculpture is the window that gives the outside world a preliminary acquaintance of the city. It has particular importance. Good urban sculpture can make the city bright with colors and send out unique charm, while far-fetched urban sculpture will not only make people feel incomprehensible, but also ruin the city's image, and will be torn down sooner or later. Mengzi is a small city with long history and thick culture. The good products from the earth of Mengzi are nature's treasures, and the greatness of the man lend glory to the city. Its cultural background has its own characteristics. The existing urban sculptures of Mengzi not really convey the cultural connotation in its entirety. Some of them are outstanding, while some of them are the least of perfection. The cultural levels will be taken into consideration below to analyze the urban sculpture of Mengzi.

i. The urban sculpture of French concession culture. The French Concession culture so to speak is the earliest impactive historical culture. After the Sino-French War, which China has won superficially but has loss in fact, China signed unequal treaty with France. Since 1889, First the French people, which in turn has a British, Italian, Japanese, Dutch successively came to Mengzi, brought Mengzi momentary prosperous. The access of foreign culture not only widen the local people knowledge, but also let the western culture developing and expansion in Mengzi. But it's regrettable that there's only some cultural relic and some record in some museums and memorial halls. There aren't many sculptures show this history. The sculptures show this period are mainly located at the New World Pedestrian Street of Mengzi. There are more than ten sculptures at the street. The sculptures reappear the representativeness incidents and interesting news during the French concession period in the form of little 
scenes. The life-size sculptures are made of bronze. The writing technique is mainly given priority to with realism. They are very vivid. When walking along the pedestrian street and coming across the sculptures ever and again, people as if met the real scene at those years, which makes people feel a lot. This kind of urban sculpture uses the technique of realism all along. It doesn't redundantly emphasize the ornamental characteristics, but it's monumentality. The use of bronze is really suit for the historical theme. The lividity bronze is just the black and white reappearance of the past time and tide. In the modern pedestrian street, the lividity sculptures can make themselves prominent, unfailing, composing and standing in the chaos. The representative works are Making Dialogues with the Foreign People, Finger-guessing Game, Delivering Letters, Bise Stockaded Village.

ii. The urban sculptures of Southwest Associated University culture. After the beginning of the War of Resistance Against Japan, the School and Art and the School of Law of Southwest Associated University and Business moved to Mengzi. Nearly all Chinese literary celebrities came here. They were teaching actively and appealing for resistance against Japan. They fused together with Mengzi people for the common ideality. They brought deep influence to the borderland county. The sculptures about the Southwest Associated University culture are the most among all the sculptures in Mengzi. From the earliest the South Lake, to the sculptures around the South Lake, to the Southwest Associated University Cultural Monument Hall, the sculpture colonies of the Southwest Associated University scattered here and there. As a commemorative historical event, the sculptures are most about the character and the incident scene about the university, which must be real exist. In fact, commemorative urban sculpture is always the main core of the urban sculpture, no matter in early 1900s, which was the rudiment of the cities in our country, or after China was founded, which the Monument to the People's Heroes led a creation agitation of monuments, or in 1980s, which was a historical period of a resurgent of urban sculpture. Commemorative urban sculpture creation, especially the paean of the revolutionary hero is almost the whole content of the large-scale urban sculptures. The representative works are: Wen Yiduo, Zhu Ziqing, The Historical Relief of the Southwest Associated University.

iii. The urban sculptures of historical famous people. Since ancient times, many historical famous people have great influence to Mengzi. Except for Wen Yiduo, Zhu Ziqing etc., which have been mentioned above, there are countless famous names which are enough to make Mengzi people proud. Some of them were coming from the other places and offered some challenges in Mengzi, some of them were Mengzi local people and had great achievements in the other places. No matter how, they all represent some period of history, and influence Mengzi people from generation to generation. Taking their images as the permanent urban sculpture can not only add the city's historical culture atmosphere, but also educate the descendant and represent our affirmation to those periods of history. The representative works are: Wang Chi, Yuan Jiagu,Chen Heting, Ma Jian, Zhu De, Miao Yuntai etc.. iv. The urban sculpture of Yunnan rice noodle. In Mengzi, the dietary culture is of long standing, and the Yunnan rice noodle is the most popular food. Various kinds of rice noodle restaurants located on high streets and back lanes in Mengzi, and Mengzi people nearly eat the rice noodle everyday. Thus, the influence of the rice noodle is really big. The legend of the Yunnan rice noodle can be dated from the Qing Dynasty. There has been more than hundreds of years. It can be said that Yunnan Rice Noodle is one of the earliest sculpture themes. In the middle of the South Lake, there stands a fabulous sculpture Love of the Bridge, which is based on the legend of Yunnan rice noodles. It was made up of glass fiber reinforced plastics painted with white paint. It was made by the craft artists in Mengzi in the early years. It shows a scene that the wife holds a bowl of Yunnan rice noodle in her both hands, the husband scholar is reallt happy and their naught son leans close to his feet. The family of three is with happiness knowing no bounds. On the stone about two meters beside the sculpture, there carved a book. As the explanatory note to the sculpture, there carved the name of the sculpture, Love of the Bridge, and the legend of the story. That's a very aesthetic legend, and the white marble applies more color to the beautiful and charming atmosphere. The modelling of the characters are mellow and full. Although there's no earthshaking momentum, and no superb skill either, the whole sculpture located among the bird's twitter and fragrance of flowers in the 
South Lake. No matter at morning or at night, taking the sky is the background, and the green tree as the background,the whole picture is so harmonious to the nature. It's impossible for the author to carve the the sculpture that Mengzi people take proud of. There are still some other representative works, such as: A Bowl A World, Three Rice Noodle Jorums.

v. The urban sculpture of pomegranate. The history of planting pomegranate in Mengzi is more than 700 years. It's named Chinese Hometown of Pomegranate by the related department of the nation. The sculpture about the pomegranate is somehow not easy to show directly, thus the patterns of the pomegranate are always carved in the style of relief on the walls of some landscape architectures, or carved at the edge of some architectures as the decoration. The urban sculpture which directly shows the pomegranate is on the Philosophers Tower of Mengzi Ten Thousand Mu Pomegranate Garden. The Philosophers Tower is a point building with eight angles and seven layers, which is combined with steel-concrete composite structure and wood carving structure. There are 88 green sandstone reliefs on the stone balustrade of the foundation of the tower. It takes the origin of the pomegranate as the principal line, and ascend the whole historical process from Persia to Mengzi and got developed from the second century A.D. to 2005 A.D.. It reappears the inalienable historical sincerity between Mengzi people and pomegranate, and shows great development that the socialist modernization that brings to the pomegranate culture. The relieves on the Philosophers Tower are like freeze-frame little film, which play the pomegranate's historical origin. Every one of them are vivid. One of them shows the great welcoming scene that Zhang Qian brought the seed of pomegranate from the western regions to China. The representative work is named The Philosophers Tower Relieves.

\subsection{The developing status of the urban sculpture of Mengzi}

In a word, there are only two developing periods of the urban sculpture of Mengzi, which are growth period and developing period.

The so-called growth period is in fact the early developing stage of the urban sculpture of Mengzi. It was about at the time that the South Lake was built that the urban sculpture began to be well-known. Most of them referred to the series of sculptures that were built together with the South Lake. The South Lake is called the Pearl in Southern Yunnan. There's a dyke in the middle of the lake called the Middle Dyke. Some of the sculptures are set around the lake, while some are dispersed in every place in the lake area. The sculptures mainly take the influential themes as the French concession, the Southwest Associated University, Yunnan rice noodle etc., and use the common texture such as stone, bronze, etc.. Their are designed realistically, which are mainly about reappear the historical events or legend. They reflect a style that is positive and propagates the local culture characteristic. At that time, the main representative works are Love of Crossing the Bridge, Wen Yiduo, the Postmen of Qing Dynasty, Zhu Ziqing etc.. The sculptures at that time were monotonous. They just simply record the event or the character at that time, and they couldn't reflect the local color at all aspects. Because of the single style and rare quantity, this is the rudimentary stage of the urban sculpture of Mengzi. Those sculptures haven't left deep cultural cognition to the Mengzi people.

The developing period of the urban sculpture of Mengzi can be dated from the 1990s till now. There are two particular periods. One of them is the early 1990s. The economy of Mengzi grew rapidly, and it brought the foundation of some landmark urban sculpture and the renovation of some historical sculptures. Another one is the early 2000s. The government of the Honghe Prefecture was moved from Gejiu to Mengzi. The structure of Mengzi was speed up. Not only there built some characteristic urban sculptures on the prefecture government's square, but also some pedestrian streets, some well-planned housing estate plots, and some schools. Compared with the sculptures before, the quantity was added, the range of the materials were expanded, and the themes were diversified. The manifestation modes and the themes of the sculptures had got great improved and diversified. The sculptures and the resident's living spaces had had more closed relationship. There appeared some representative urban sculptures. 


\section{The Cultural Connotation and the Characteristics of the Urban Sculpture of Mengzi}

\subsection{Paying attention on expressing and reflecting the historical culture of Mengzi}

Mengzi is an outlying town. It was a vital communication lien in southern Yunnan. After the Sino-France War, Mengzi became the French concession. It's an unique history. The foreigners came here and opened many trading companies here, which brought Mengzi great influence no matter on architectural but also culture. Although the teachers and the students of the Southwestern Associate University just stayed in Mengzi for several months., the culture brought to Mengzi was combined with the local culture, and gave birth to many articles, poems, and stories, which became a glorious history of Mengzi. The urban sculptures in Mengzi grip its historical and cultural theme, and fully express the history and culture. The history of Mengzi also endow the urban sculpture some cultural connotation otherwise.

\subsection{Standing out the local traditional cultural characteristics}

The range of the local culture can be quite wide. It can refer to handicraft, catering, metal and education etc.. The main local culture of Mengzi is catering. It has the good names called Chinese Hometown of Yunnan Rich Noodle, Chinese Hometown of Pomegranate. The Yunnan rice noodle and the pomegranate is widely known in Mengzi. In the time of vigorously propagating the importance of the traditional culture to the city, the constructing of the urban sculptures is an important way to developing the traditional culture. The urban sculpture has chosen the Yunnan rice noodle and pomegranate as the theme. Some of them directly show the scene of eating Yunnan rice noodle,while some of them show the jorum used for eating the rice noodle. Especially the classical sculpture of Love of Crossing the Bridge vividly shows the beautiful and charming legend. It's the proud of Mengzi people. The relieves on the base of the Philosophers Tower of Mengzi Ten Thousand Mu Pomegranate Garden show the history and legend of Mengzi Pomegranate, and there's detailed character engrave on every on piece of the relief. They not only bring Mengzi people visual enjoyment, but also proud to the local cultural characteristics.

\subsection{Embodying the city spirit of Mengzi}

The urban sculpture is suit for the city's spirit. Mengzi is a developing city. Inheritance and development is the developing idea of the city, and the magic key help the city go to the world. It the spirit of the city. Mengzi is working hard to develop various of industries based on the traditional foundation all the time. It opens its door to the outside world, and gets constant improvement on politics, culture, education,economy, transportation etc.. It always show its unique charm to the outside world with a positive status. Based on the local culture, Mengzi people are diligent and plain, hospitality, happy and motivate. It's just the city's mind and character: good at absorbing other regions' cooperation and development experience. The urban sculptures embodies the city's spirit. The sculpture Heavenly Horse is the typical one that express the city's spirit. In the period of rapid economic growth, the heavenly horse just stands for the good will of the taking-off of the city. The position that the sculpture locates is the juncture of the old and new town. From the sculpture west to the prefecture government's building is the core area of the new town of Mengzi. The sculpture just locates at the center district. The sculpture of Heavenly Horse is no matter the embodiment of the spirit of struggling and developing.

\subsection{Distinct flavor of the time}

The authors of the urban sculptures of Mengzi has their own thought. It's not only shown on its communication with the traditional sculptures, but also on selecting suitable material. They don't only choose the traditional materials such as bronze, stone, wood etc., but also pay attention on diversified development. They are good at giving play to their own rich resources. Just like taking the tin stone from Gejiu as the sculpture material to do the sculpture A Bowl, A World. It not only proclaims the traditional culture, but also show a innovative style. It possesses great spirit of time. The authors use modern urban sculptures and historical culture to express people's hope and blessing to the culture and the future of Mengzi, and reflect the age-old traditional culture, unique regional culture, and think internalization and modern atmosphere of Mengzi City. 


\section{Conclusion}

It takes the historical story us the main theme, and circular engravure as the main skill. The circular engravure sculpture has good integrity and visual effect. Moreover, trying to take local tin stone to make the sculpture stands out the local color, and combined with its cultural connotation. It suits the local character not only on art, but also on culture. It makes the local core prominent, and improves the city's cultural taste. Culture is the soul of the modern city. It's hoped that the sculpture of Mengzi can keep the foothold on exploring the cultural characteristics, embody the distinctive individuality and unique style of Mengzi combined with its own characteristics. As a isotopic carrier, the urban structure calmly and quietly express the cultural connotation of Mengzi with its unique are language. The quiet art yet improves the cultural taste of Mengzi, which make it has more own cultural characteristics. The way of developing the urban sculpture in Mengzi will be long. It needs the help from various aspects. The cultural characteristics of Mengzi will give the sculptures more connotative charm, and real excellent sculptures will make the city more mature and charming.

\section{Reference}

[1] Entering the Mengzi Southwest Associated University. [EB/OL]. http://blog.sina.com.cn/s/blog_4dee6dba01013fh1.html

[2] The Culture of Mengzi [EB/OL] . http://www.mengzi.gov.cn/Article/163.html

[3] An Introduction to Mengzi [EB/OL]. http://www.doc88.com/p-406509908839.html

[4]Chen Xin. A Study about the Urban Sculpture Design on Embodying the Regional Culture. [D]. Changsha. Central South University of Forestry and Technology, 2010. 